\title{
PERSPECTIVA TEÓRICO-METODOLÓGICA DA EDUCAÇÃO AMBIENTAL NA ESCOLA
}

\author{
Maria Inêz Oliveira Araujo ${ }^{1}$ \\ Patrícia Domingos ${ }^{2}$
}

\begin{abstract}
Resumo
O sistema escolar brasileiro em muito dificulta a implementação da educação ambiental na escola. Diferentes ações, buscam inserir as questões socioambientais nas práticas pedagógicas, no sentido de possibilitar aos seus alunos o desenvolvimento de atitudes e de valores éticos que vislumbrem a sustentabilidade socioambiental. Nesse sentido, o presente artigo buscou verificar como a educação ambiental está sendo tratada nas escolas. Para tanto, buscamos evidências sobre macrotendências: práticas pedagógicas e inserção das questões ambientais nos currículos, em 26 artigos apresentados no IX Encontro Pesquisa de Educação Ambiental. Os resultados mostram que a comunidade escolar, em enfrentamento às adversidades, busca desenvolver e implementar a educação ambiental crítica, mediante práticas multidisciplinares.
\end{abstract}

Palavras-chave: EPEA. Contextos escolares. Ambientalização curricular.

\section{METHODOLOGICAL THEORETICAL PERSPECTIVE OF ENVIRONMENTAL EDUCATION IN SCHOOL}

\begin{abstract}
The Brazilian school system greatly hinders the implementation of environmental education in school. Different actions seek to insert socio-environmental issues in pedagogical practices in order to enable their students to develop attitudes and ethical values that envision social and environmental sustainability. In this sense, the present article sought to verify how environmental education is being treated in schools. Therefore, we searched for evidence on macro trends: pedagogical practices and insertion of environmental issues in curricula, in 26 articles presented at the IX Environmental Education Research Meeting. The results show that the school community facing adversity seeks to develop and implement critical environmental education through multidisciplinary practices.
\end{abstract}

Keywords: EPEA. School contexts. Curricular ambientization.

\section{PERSPECTIVA TEÓRICO-METODOLÓGICA DE LA EDUCACIÓN AMBIENTAL EN LA ESCUELA}

\section{Resumen}

El sistema escolar brasileño en muy dificulta la implementación de la educación ambiental en la escuela. Diferentes acciones, buscan insertar las cuestiones socioambientales en las prácticas pedagógicas en el sentido de posibilitar a sus alumnos al desarrollo de actitudes y de

\footnotetext{
${ }^{1}$ Doutora em Educação pela Universidade de São Paulo. Professora titular da Universidade Federal de Sergipe. inez@ufs.br

2 Doutorado em Biotecnologia Vegetal pela Universidade Federal do Rio de Janeiro. Professora Adjunta do Instituto de Biologia da Universidade do Estado do Rio de Janeiro. patvitesse@gmail.com
} 
valores éticos que vislumbre la sustentabilidad socioambiental. En este sentido, el presente artículo buscó verificar cómo la educación ambiental está siendo tratada en las escuelas. Para ello, buscamos evidencias sobre macrotendencias: prácticas pedagógicas e inserción de las cuestiones ambientales en los currículos, en 26 artículos presentados en el IX Encuentro Investigación de Educación Ambiental. Los resultados muestran que la comunidad escolar en enfrentamiento a las adversidades, buscan desarrollar e implementar la educación ambiental crítica, mediante prácticas multidisciplinares.

Palabras clave: EPEA. Contextos Escolares. Ambientalización curricular.

\section{Introdução}

$\mathrm{O}$ atual contexto socioambiental, em termos mundiais e particularmente em termos nacionais, destaca o aprofundamento das desigualdades, da injustiça ambiental pelo avanço de processos desenvolvimentistas sobre sistemas naturais e culturas tradicionais.

Esses processos ganharam vulto no recente período do chamado ciclo de commodities do Brasil, principalmente com atividades de exploração de petróleo, da mineração e do agronegócio, cujos crescimentos justificaram o aumento da escala de degradação em várias dimensões da vida, aprofundando a concentração de renda e ampliação dos processos de destruição de áreas naturais, com a chancela da legalidade, o que nos induz a esquecer que:

$\mathrm{O}$ ambiente, ao ser definido como bem comum, implica em possibilitar a todos e todas as condições coletivas para a realização pessoal e na garantia jurídicoinstitucional de que a natureza só pode ser apropriada para fins de atendimento de necessidades socialmente justas, subordinando o interesse privado ao interesse público e coletivo (LOUREIRO, 2015 p.59).

Associado a esse quadro, o Brasil vivencia, atualmente, momentos de extrema insegurança política, ambiental e social, relacionados ao rompimento institucional, que teve curso em 2016, no âmbito da política nacional de governo.

Nesse contexto, emerge a necessidade de uma educação que promova a criticidade e a vontade de participar dos destinos da sociedade. Nesse sentido, Loureiro (2015, p.47) argumenta que um "aspecto mais de fundo, diz respeito às finalidades da educação. 'Educar para...' dá a entender que se educa com fins instrumentais, que podem estar dissociados de fins emancipatórios e reflexivos". Assim, o ensino, antes visto como instrumento de transmissão de conteúdos, passa a assumir o processo de formação de valores e de sujeitos para a transformação de sua realidade.

É inegável a importância dos saberes que os professores adquirem durante sua formação, seja ela inicial ou continuada, para desenvolverem atividades que promovam a educação ambiental com seus alunos. Nesse sentido, a ação do professor ou professora sob a égide da educação ambiental não pode desconsiderar as questões ambientais presentes no cotidiano. O exercício vai além da transmissão de conhecimento, busca manter a atmosfera do saber vivo, ativo, participativo.

A escola, instituição social e de cultura responsável por iniciar a formação geral do cidadão, deve buscar um processo educativo que promova, em suas práticas, a reflexão sobre as questões e problemas socioambientais. Portanto,

[...] tem o papel específico que não pode ser confundido como papel de outros muitos agentes educativos não escolares. Se a educação ambiental, como educação, tem especificidades - principalmente, a de educar para uma relação mais equilibrada das sociedades com a natureza - e a escola também tem o papel específico- a socialização dos saberes sistematizados - papel da escola com a educação ambiental 
é o de socializar os saberes ambientais elaborados pela cultura em toda sua trajetória histórica (TOZONI-REIS; CAMPOS, 2015 p.121)

Partindo do conceito de educação ambiental estabelecido durante a Conferência de Tbilisi, em 1977, a prática pedagógica deve contemplar o estudo do meio ambiente em toda sua complexidade, não negligenciando as relações sociais, tecnológicas, ecológicas, políticas e outras, mediante procedimentos interdisciplinares e que busquem a sustentabilidade socioambiental e uma melhor qualidade na vida para todos os seres vivos do planeta.

Desenvolver práticas, atendendo esses critérios, não é algo fácil de ser realizado nas escolas. O currículo, o sistema administrativo, as concepções dos gestores e as condições dos recursos fazem a implementação da educação ambiental em contexto escolar uma tarefa difícil. Por exemplo, apesar de se falar muito em interdisciplinaridade, ainda entendemos como um campo em construção, pois trata-se de um conceito complexo, polissêmico, que impõe dificuldades tanto para sua conceituação teórica, como também para implementar-se em projetos e ações que visem a construção do conhecimento complexo dos objetos.

De acordo com Araujo (2004 p.72), as "peculiaridades, presentes nos conceitos complexos envolvidos nessa perspectiva de interação disciplinar no ensino e na pesquisa, fazem da interdisciplinaridade um processo que enfrenta dificuldades e armadilhas que vão desde o âmbito epistemológico ao campo metodológico.

A expectativa de que o professor reconheça a limitação de sua racionalidade disciplinar, a insatisfação com a fragmentação do saber, para que a necessidade de aprender com outras áreas, como propõe Japiassu (1976, p.138):

$\mathrm{O}$ verdadeiro espírito interdisciplinar consiste nessa atitude de vigilância epistemológica capaz de levar cada especialista a abrir se às outras especialidades diferentes da sua, a estar atento a tudo o que nas outras disciplinas possa trazer um enriquecimento ao seu domínio de investigação e a tudo o que, em sua especialidade, poderá desembocar em novos problemas e, por conseguinte, em outras disciplinas.

Fazenda (1979) admite que a interdisciplinaridade demanda ações que sejam motivadoras de um movimento no interior da escola, o que muitas vezes esbarra em sentidos subjetivos determinados por normas curriculares e de gestão.

A construção de planejamentos e ações interdisciplinares é, também, reconhecida como de grande dificuldade na escola, (VEIGA-NETO, 1997), porém, se seus membros desejarem implementar a educação ambiental na escola, precisam planejar e desenvolver práticas interdisciplinares, considerando que objetos de estudo e de pesquisa não são exclusivamente de um único campo disciplinar.

A educação ambiental, desde que dedicada a dar visibilidade aos conflitos socioambientais presentes no território escolar, o que pressupõe lidar com a realidade complexa e, portanto, incapaz de ser entendida em uma lógica disciplinar, se configura como uma possibilidade para a aproximação de práticas interdisciplinares na escola, com as mesmas dificuldades já apresentadas.

Dessa forma, as práticas educativas sob a égide da educação ambiental nas escolas devem possibilitar mudanças de paradigmas para alcançar a sustentabilidade num sentido de redução de desigualdades socioambientais e perpetuação das formas de vida. De acordo com Coutinho, Da Luz e Santiago (2017, p.2):

PCN destacam que a instituição escolar precisa fornecer condições para despertar o questionamento dos alunos frente à realidade vivida, orientando-os a desenvolver um espírito de crítica às induções ao consumismo, bem como o senso de responsabilidade e solidariedade no uso dos bens comuns e recursos naturais, de modo a respeitar o ambiente e as pessoas de sua comunidade. 
O ponto de partida para a implementação da educação ambiental na escola se dá mediante a concepção e o compromisso que professores e gestores têm sobre e com educação ambiental, principalmente quando se trata de reconhecer a sua importância na formação de uma nova mentalidade socioambiental. Assim, a pergunta frequente nos espaços de reflexão e formação em educação ambiental é como a educação ambiental se faz presente no contexto do ensino formal.

\section{Procedimento metodológico}

Nessa direção, este artigo busca evidenciar as tendências epistemológicas e metodológicas da educação ambiental presentes nas pesquisas desenvolvidas sobre a educação ambiental no contexto escolar.

Para tanto, buscamos apenas os artigos apresentados e publicados no IX Encontro Pesquisa em Educação Ambiental - EPEA, realizado em Juiz de Fora, Minas Gerais no período de 13 a 16 de agosto de 2017, tomados como indícios que sinalizam as tendências de pesquisas em EA nas escolas.

De acordo com o site geral do EPEA, esse evento surgiu do esforço de grupos de pesquisadores de São Paulo, vinculados ao programa de Pós-Graduação em Educação da UNESP e da USP de Ribeirão Preto, e o Programa de Pós-Graduação em Ecologia e Recursos Naturais da UFSCAR, para criar um espaço de reflexão, divulgação e aprofundamento de pesquisas em Educação Ambiental. Ainda, de acordo com o site:

Embora o campo da pesquisa em educação ambiental no Brasil, já no início deste século mostrasse sinais claros de um caminho de consolidação, constatamos que poucos eram os espaços para compartilhamento dos conhecimentos que vinham sendo produzidos por esta comunidade de pesquisadores. Também ainda são poucas as iniciativas de sistematização e reflexão dessa própria produção (EPEA, 2018, $\mathrm{s} / \mathrm{p})$.

Foi com esse pensamento que, em 2001, foi realizado o primeiro EPEA, na UNESP de Rio Claro. Essa primeira edição foi tão marcante, que a conferência de abertura precisou ser realizada numa igreja, pois o local reservado não comportava o número de inscritos. A elevada procura por esse objeto de estudo evidenciou a necessidade de ser criado esse espaço. Paralelamente, nas reuniões da ANPED, ocorreu um movimento para o GT- 22, que, assim como o EPEA, se configurou em mais um espaço para apresentar e refletir sobre resultados de pesquisa em educação ambiental. Porém, o GT-22 da ANPED, devido à formatação e normas orientadoras das reuniões da ANPED, limita o espaço de apresentação dos trabalhos, reduzindo o número de aprovações e, em consequência, restrição de acesso à comunidade de pesquisadores brasileiros dos conhecimentos elaborados em todas as regiões e em todos os níveis.

O Encontro de Pesquisa em Educação Ambiental, com periodicidade bianual, busca reunir especialistas que vêem produzindo conhecimento sobre bases teóricas, práticas e sobre o campo da Educação Ambiental no Brasil. Assim, tem como objetivo discutir, analisar e divulgar trabalhos de pesquisa em EA. Especificamente, busca:

Aprofundar as discussões sobre as abordagens epistemológicas e metodológicas das pesquisas em EA; Identificar práticas de pesquisas em EA que vêm sendo desenvolvidas no âmbito dos programas de pós-graduação e em outros espaços institucionais e não-institucionais (EPEA, 2018, s/p). 
Nessa direção, o EPEA inova quando substitui o GT - grupo de trabalho, pelo GDP grupo de discussão de pesquisa. Essa transformação de GT para GDP faz toda diferença em relação aos eventos tradicionais. Esse Encontro, além de permitir a apresentação e discussão de pesquisas individualizadas, abre um espaço - GDP - para discussão sobre as pesquisas em um eixo temático específico.

Portanto, concordamos com o que está posto no referido site: "o EPEA, como outros esforços de socialização e discussão da pesquisa no país, tem cumprido um papel de grande significado neste contexto, oferecendo à comunidade de pesquisadores um espaço acadêmico para discussão da pesquisa", incluindo as pesquisas realizadas com e na escola. Portanto, também se constitui em espaço de formação continuada para professores interessados em educação ambiental.

Vale ressaltar que dos 117 (cento e dezessete) trabalhos aprovados, nos (08) oito Grupos de Discussão de Pesquisa do EPEA de 2017, 26 (vinte e seis) foram aprovados no GDP - EA em Contexto Escolar, cerca de 30\%, o que, em nossa opinião é um dado expressivo para justificar esse trabalho.

\subsection{Trabalhos aprovados}

1. Pertencimento e educação ambiental: reflexões iniciais

2. Jogos Didáticos para o Ensino de Ciências com ênfase na Educação Ambiental

3. A construção do objeto de pesquisa em educação ambiental crítica: reflexões a partir de escolas municipais em Duque de Caxias, RJ.

4. O "Conteúdo Básico Comum": articulações entre a Física e a Educação Ambiental estabelecidas pela proposta curricular de Minas Gerais.

5. Problematizações Socioambientais: o que dizem os Projetos de Educação Ambiental elaborados e implementados por duas escolas da rede estadual de ensino pertencentes à jurisdição da SRE/Juiz de Fora.

6. A Teoria Ator-Rede como instrumento para investigar a aprendizagem em uma trilha ecológica.

7. Educação ambiental crítica na relação universidade/escola: narrativas docentes.

8. A formação de conceitos científicos no contexto da horta escolar enquanto Espaço Educador e Sustentável.

9. A educação ambiental do projeto "lê melhor quem lê o mundo"

10. O desastre da Samarco: a cobertura de diferentes mídias e sua importância para a educação ambiental

11. Apontamentos para uma educação ambiental intercultural em escolas de Bogotá.

12. As perspectivas de ambiente e de Educação Ambiental nos projetos de professores da Educação Básica em um curso de formação continuada.

13. Leis de Proteção à Flora: Estudo de Caso com Alunos de uma Escola Pública de Ensino Fundamental do Vale do Ribeira-SP

14. Discutindo os Riscos e a Vulnerabilidade Ambiental no Estado capitalista: a proposta de uma Educação Ambiental como ato político.

15. Interfaces entre Gestão Escolar e Educação Ambiental Crítica: um estudo no Ifes/BR

16. Educação ambiental e educação aberta e à distância na formação de professores: reflexões iniciais

17. A horta como espaço de educação ambiental na escola 
18. Proposta de uma sequência didática na construção do conhecimento em educação ambiental

19. Educação Ambiental: o fazer docente em uma escola pública do município de Marituba/Pará

20. A categoria de espaço geográfico enquanto possibilidade na construção de uma educação ambiental crítica na geografia escolar

21. Ambientalização curricular: a relação sociedade natureza em cursos de Ciências Biológicas, UFCG, PB

22. Mapeando as hortas escolares na rede pública estadual de Juiz de Fora, MG

23. Discurso de estudantes sobre a relação do Aedes aegypti e o saneamento básico no entorno escolar

24. Educação ambiental e o uso de agrotóxicos: possíveis relações entre a educação e o mundo do trabalho

25. A temática dos conflitos socioambientais nas pesquisas em educação ambiental: análise de teses e dissertações

26. Bogotá una ciudad no preservadora de ecosistemas urbanos ¿De qué manera el futuro sustentable de Bogotá se relaciona con la conservación y preservación de los humedales?

Partindo dos argumentos, a pesquisa de caráter descritivo, utilizou 26 artigos apresentados ao GDP - Educação Ambiental em contextos escolares. Buscamos identificar, nos diferentes artigos, sinais e indícios que pudessem vislumbrar pesquisas que contribuam para o aprofundamento teórico e metodológico no campo da educação ambiental das questões referentes a macrotendências, as metodologias adequadas para a implementação da educação ambiental e as iniciativas de ambientalização curricular.

\section{Análise interpretativa}

Os dados foram agrupados a priori em duas categorias de análise. As contribuições apresentadas pelos trabalhos participantes trouxeram algumas características comuns, cuja predominância está na macrotendência, Proposições elou recomendações para uma educação ambiental crítica e outra ambientalização curricular.

Na categoria Proposições e Recomendações para Educação Ambiental Crítica, os trabalhos apresentaram a preocupação em trazer proposições para a construção de uma educação ambiental escolar crítica.

A eleição pelas práticas da Educação Ambiental Crítica (EAC) e, particularmente da Educação Ambiental Escolar Crítica, partem do reconhecimento do quadro de injustiça socioambiental gerado pelo contexto do capitalismo.

Nesse sentido, destaca-se a necessidade de explicitar o risco e vulnerabilidade ambiental produzidos pelo estado capitalista no qual estamos imersos. Um dos textos aponta para a escassez de trabalhos de EA e os contextos de vulnerabilidade ambiental.

Tomando como referência o espaço urbano, destaca-se a expansão de áreas periféricas urbanas como resultado das injustiças socioambientais que relegam uma fração da população à ausência dos serviços públicos sob responsabilidade do estado. Esses serão os agrupamentos humanos mais vulneráveis. O Estado capitalista tem, assim, um papel central na geração e reprodução de tais injustiças. 
A pesquisa com escolas de periferias também é incluída nas considerações de outros países latino-americanos, no caso Colômbia, cujo contexto macroeconômico de capitalismo dependente é o mesmo de nossa realidade.

Mais uma vez, a vulnerabilidade surge associada aos grupos de periferia, num sentido social e também cultural. Há um entendimento de que a EA pode ser colaboradora para uma tradução cultural em escolas desse contexto. Considerações interculturais de EA incluem as relações de poder da sociedade e seus discursos, apontando para uma perspectiva política crítica e para a necessidade de promoção de justiça social.

Escolas públicas de periferia urbana de Bogotá são apontadas como uma potente possibilidade para trabalhos de ação transformadora e, aqui, consideramos que, num certo sentido, o mesmo pode ser proposto às escolas de periferia de grandes cidades latinoamericanas. Assim:

A partir da problematização do papel das escolas públicas no mundo contemporâneo, propomos que as escolas localizadas perifericamente nas áreas urbanas de Bogotá sejam pensadas como locais de tradução cultural. Estes espaços escolares são catalisadores de constantes contatos afetivos entre seres humanos que expressam em suas práticas uma grande diversidade e riqueza de repertórios simbólicos, produzidos desde uma multiplicidade de heranças culturais e histórias de migração, exclusão e marginalização (MOLANO; ALMEIDA, 2017, p.5).

Essa percepção remete à discussão da educação ambiental que se pretende no contexto escolar, reconhecendo que educação é, além de um ato de conhecimento, um ato político e, portanto, não há pedagogia neutra (FREIRE, 2002). Dessa forma, nossas opções pela prática pedagógica como um todo e, em particular pela EA, estão relacionadas a uma opção política, mesmo que irrefletida. A educação pode ser considerada uma forte aliada das possibilidades de discussão e transformação de tais injustiças, desde que feita uma opção clara por não tornála um instrumento de preceitos para a conformação da realidade injusta desde a infância e juventude.

Enquanto docentes comprometidos com uma educação emancipatória, nos cabe reconhecer que:

[...] embora esse posicionamento não seja fácil, ele alimenta uma das principais frentes de luta da sociedade brasileira, em que o papel de nós educadores não se restringe aos ensinamentos conteudísticos. Nossa tarefa exige comprometimento e engajamento, a fim de superar as injustiças socioambientais. Essa superação apenas se concretizará a partir do momento em que concebermos que a educação não é neutra e que o nosso papel ultrapassa o de lecionar os conteúdos aos quais estamos habilitados. Temos a obrigação de sermos mediadores de um modelo de educação que não se adapta, que não se entrega aos fetiches do modelo neoliberal vigente. Longe de fazer quaisquer proselitismos, nosso papel não se resume a meros transmissores de conhecimento. Devemos, acima de tudo, assumirmos nosso papel revolucionário na contramão das injustiças resultantes desse modelo perverso. (ANDRADE; PINTO, 2017, p.11).

Uma estruturação escolar a partir de projetos transversais, que se aproxima ao já proposto por Hernandez (1998), discute a limitação do conhecimento disciplinar para o trabalho desejado e recomenda aos educadores ambientais,

[...] entendidos(as) como tradutores(as) culturais, [que] devem considerar que a transmissão dos conteúdos está sujeita aos conflitos de interesse, às mudanças de contextos, à aleatoriedade da interação comunicativa e outros fatores. .... Espera-se, desse modo, que o(a) Educador(a) Ambiental socialize com seus alunos não tanto os produtos sempre transitórios e altamente instáveis das traduções, mas, fundamentalmente, a própria arte de traduzir (MOLANO; ALMEIDA, 2017, p.5). 
E, por fim, a EAC almejada, tem a contribuir, enquanto ação emancipatória, para avanços na EA escolar, uma vez que:

A educação ambiental pode ser uma possibilidade de enfrentamento dos limites postos pelos conflitos socioambientais, mas também pode ser um potencial mobilizador, emancipador, no sentido da emancipação e do empoderamento dos grupos sociais em situação de vulnerabilidade. Propõe-se, na verdade, uma educação ambiental vinculada a uma base reflexiva, que seja trabalhada de forma transdisciplinar, na qual a conscientização e a preservação permaneçam juntas. $\mathrm{O}$ intuito é modificar a relação das pessoas com a Natureza e desenvolver uma cidadania ambiental oriunda de um processo pedagógico (ANDRADE; PINTO, 2017, p.12).

Tomar a realidade como totalidade é a perspectiva necessária para a realização de uma EAC que possa contribuir para a superação da lógica fragmentada, característica da sociedade atual.

Nessa perspectiva, uma proposição realça a necessidade do sentimento de pertencimento para a formação do educador ambiental e recomenda a construção de trajetos alternativos ao caminho único nas ações de uma educação ambiental que se propõe transformadora.

Dessa forma, se reconhece a necessidade do desenvolvimento de eixos formativos contra hegemônicos que busquem romper com a armadilha paradigmática predominante, de acordo com Graúdo e Guimarães (2017), na qual há uma perspectiva de mundo racional e fragmentado.

A superação dessa perspectiva recruta um movimento coletivo e conjunto, a fim de que se crie uma ruptura, seguida de um avanço em relação ao pensamento simplificador que promove a separação entre sujeito e o objeto, o homem da natureza, ou, na perspectiva de Morin (2000), da disjunção e redução em oposição ao pensamento complexo. Essa superação, quase sempre, não se dá por um esforço individualizado do professor, mas de um movimento escolar, presente no projeto pedagógico da escola.

À categoria de trabalhos caracterizada por pesquisas que buscam evidenciar referências de indicadores para o reconhecimento de uma visão mais crítica em comparação a práticas escolares mais conservadoras, intitulou-se como Indicadores da Educação Ambiental Crítica. Os trabalhos nela inseridos demonstram uma preocupação com o encaminhamento de metodologias e referenciais que colaborem para o avanço de concepções e práticas críticas de EA.

Com relação a tais indicadores desde a construção e delimitação do objeto de pesquisa em EAC, pode ser observada a busca de referenciais que garantam a incorporação de conflitos socioambientais da localidade da escola. Assim,

[...] analisar a construção do objeto de pesquisa do educador ambiental, considerando a EAC implica avaliar quais os elementos no interior e no entorno da escola podem se configurar em sujeitos que confiram materialidade a essas ações intencionais, contextualizadas, questionadoras e emancipatórias e EA (LOUREIRO; FLORIANO 2017, p.5)

A perspectiva de ações e projetos de EA que buscam produzir o consenso sobre problemáticas socioambientais, a acomodação e a invisibilização da disputa de interesses de classes em processos econômicos locais é retratada como um indicador de alerta a se superar. Tais proposições de EA ocorrem por parte de algumas empresas e ONGS, visando que sejam desenvolvidas no interior de escolas. Dessa maneira: 
[...] o que está em jogo ao se pensar e delimitar o objeto de pesquisa na EAC são as condições de existência material das classes subalternas, frente a um projeto de desenvolvimento que espolia a natureza e explora os trabalhadores, mas que é "consentido" socialmente devido à capacidade dos aparelhos privados de hegemonia do capital em esvaziar o caráter público da educação e instituir processos que educam para o consenso, ou seja, para a naturalização das relações econômicas e a organização de um Estado que reproduz as formas de dominação de classe (LOUREIRO; FLORIANO 2017, p.10)

Sugere-se, então, que alguns elementos constituintes de um trabalho contrahegemônico em EA são indicadores a serem buscados a fim de trazer para a proposta uma perspectiva verdadeiramente crítica da realidade. Segundo Spolaor e Cosenza (2017), esses elementos seriam a problematização do contexto da realidade, as injustiças e conflitos socioambientais locais.

Essas considerações pretendem orientar as práticas educativas para superarem a visão individualizada sobre as problemáticas e soluções ambientais, que sobrepõem a questão do problema às de suas causas, assim como a perspectiva pontual de trabalhos escolares e o ativismo (FREIRE, 2011) ou praticismo (LOUREIRO, 2010) irrefletido da prática cotidiana, que podem estar presentes em trabalhos de EA escolar.

Assim, há que se buscar, como proposto por Tozoni-Reis (2008) a problematização do contexto local e a configuração dos sujeitos sociais, em toda sua complexidade para a discussão na escola. Nesse movimento, merece ênfase a identificação de determinantes sóciohistóricos da realidade local, enfim buscar o entendimento não do problema, mas de suas causas e das relações que os produzem e mantêm em determinados territórios.

A explicitação de conflitos é um segundo referencial apontado (SPOLAOR; COSENZA, 2017), uma vez que a sociedade é o espaço do conflito que tende a ser apagado e silenciado pelas forças dominantes.

Assim, uma vez que "conflitos são inerentes a qualquer sistema social, [...] essa configuração [...] precisa ser exteriorizada, visibilizada e reconhecida como intrinsecamente relacionada aos princípios e preceitos democráticos (MALAGODI, 2013 apud SPOLAOR; COSENZA, 2017, p.5).

Da mesma forma a EA no contexto escolar deve orientar seus trabalhos para dar visibilidade ao quadro de injustiça que o sistema hegemônico torna invisível. Dessa forma, cabe conceber

[...] a Educação Ambiental a partir do seu comprometimento com questões sociais, políticas, econômicas, ecológicas, culturais e ideológicas que se encontram intimamente relacionadas com degradações, injustiças e conflitos socioambientais, reconhecendo a relevância do papel desempenhado pelas escolas quanto ao desenvolvimento de práticas pedagógicas capazes de assumir o compromisso social de visibilizar omissões e dissimulações, evidenciar inércias e diligências e descortinar vulnerabilidades e destrutibilidades concernentes a injustiças socioambientais (COSENZA; KASSIADOU; SÁNCHEZ, 2014 apud SPOLAOR; COSENZA, 2017, p.2).

Algumas avaliações de pesquisas realizadas com professores e suas produções concluem sobre o aumento de trabalhos que se caracterizam como participativos (ROSA et al., 2017) elaborados, remetendo ao esforço de docentes comprometidos com seu papel profissional e com a escola pública, apesar de registrar a necessidade de amadurecimento profissional e/ou formação complementar para essa elaboração.

Nesse sentido, apontam que professores se empenham em trabalhar "fazendo ponte com a realidade dos alunos" (FIGUEIRA; LIMA; SELLES, 2017, p.4) e que a predominância 
de trabalhos com uma vertente mais conservadora pode ser, muitas vezes, relacionada às diferentes histórias de vida dos sujeitos e diferentes áreas de formação profissional (ROSA et al., 2017).

Na categoria Ambientalização curricular foram incluídos trabalhos orientados para a preocupação em aproximar a EA do currículo escolar ou universitário, considerando como base os conteúdos disciplinares previstos nos currículos.

$\mathrm{Na}$ perspectiva da formação profissional universitária cabe o interesse em evidenciar de que maneira a questão ambiental se apresenta no currículo. Essa conceituação pode ser apresentada de forma restrita a uma concepção de meio ambiente natural, que compreende a fauna e a flora.

A formação de futuros profissionais que têm um potencial de aproximação, por dever de ofício, com sistemas naturais, como a Biologia, a Geografia, não pode prescindir da discussão sobre como as relações sociedade-natureza são determinadas pelas expressões de poder do modelo econômico capitalista. Sob outra ótica, a disciplinarização e consequente compreensão fragmentada da realidade (LOUREIRO, 2003) remete a concepções mecanicistas e à busca de soluções técnicas e pragmáticas para problemas complexos. A formação de professores dessas áreas assume uma dimensão ainda mais grave pela replicação dessa concepção no ensino básico. Assim:
A própria produção acadêmica da geografia evidencia essa dicotomia, onde predomina a pouca articulação dos elementos naturais com fenômenos sociais [...]. Essa lógica de ensino aparece no tratamento das questões ambientais no ensino de Geografia, que em geral são vistos numa perspectiva de causa e efeito [...] Como resultado dessa fragilidade na formação de professores, o ensino de geografia, ainda hoje, encontra-se esvaziado de sentido, fragmentado, o que resulta na apreensão parcial da realidade, [...] os conteúdos são desenvolvidos sem levar em conta a realidade concreta da vida dos educandos, o que diverge radicalmente de uma perspectiva crítica de ensino, e consequentemente torna impossível a construção de uma educação ambiental crítica (OLIVEIRA; LOUREIRO, 2017, p.5).

A maioria dos trabalhos na categoria Ambientalização curricular pretende discutir formas de inserção da EA nos currículos da educação básica, a partir de determinados temas que dialoguem com a perspectiva ambiental, ou apresentam atividades com esse objetivo, como exemplo introduzir a horta, discutir problemas ambientais do entorno da escola.

As questões orientadoras poderiam ser resumidas nas seguintes proposições: Como a EA pode ser inserida em determinada disciplina?, ou De que maneira esta é uma prática capaz de estabelecer diálogo entre a EA (tanto conservadora como crítica) e a determinada disciplina? Nessa perspectiva, a pesquisa documental curricular foi uma estratégia eleita por alguns trabalhos, a fim de avaliar as melhores oportunidades curriculares, considerando os conteúdos mais afeitos à discussão ambiental e estabelecendo um diálogo com essas possibilidades.

Parte dos trabalhos relata ações realizadas em escolas e a discussão sobre sua efetividade para a aprendizagem para, a partir daí, promover uma discussão ambiental ou socioambiental em torno do tema. Ainda se observa maior recorrência das práticas de EA em relação às disciplinas de Ciências/Biologia e Geografia, embora outras, como Física, tragam esforços para essa aproximação.

Alguns desses trabalhos foram estruturados sobre atividades extraclasse, como trilhas ecológicas, realização de hortas, clube de ciências, valorizando o conhecimento local que permite a exploração e interrogação sobre realidades mais imediatas como ponto de partida, 
enquanto outras atividades educativas como jogos e atividades lúdicas em geral se voltaram a testar os materiais ou práticas de EA nas escolas, seguindo roteiros pré-elaborados ou sequências didáticas pertinentes.

A valorização da interdisciplinaridade foi uma referência recorrente em alguns desses trabalhos, demonstrando a necessidade de ações que envolvam diferentes componentes curriculares, a fim de evitar uma perspectiva reducionista de meio ambiente. Esse aspecto traduz uma compreensão de mundo fragmentada, focada na parte. "Privilegiando uma dessas partes, o ser humano, sobre as demais, natureza, estabelece uma diferença hierarquizada que constrói a lógica da dominação" (GUIMARÃES, 2004, p.27). Segundo esse viés, a concepção fragmentada, predominante no ensino escolar, se encontra na contramão da aposta da EA escolar como potencial crítico e transformador da realidade.

Assim, as práticas escolares sob uma lógica ultra disciplinar, conteudistas, não são adequadas para a perspectiva de trabalho que pretende tratar o meio ambiente e a realidade em sua totalidade, já que, "não é adequado estabelecer hierarquias entre os aspectos que compõem o ambiente, pois, em sua integridade, esses aspectos são linhas de ação complementares que permitem uma EA emancipatória" (MOLANO; ALMEIDA, 2017, p.9).

Ainda, reconhece-se que "Nesta reflexão encontra-se a chamada para a interdisciplinaridade e a transversalidade da EA, que permita respeitosos cruzamentos de fronteiras, onde nenhuma disciplina tenha a hegemonia nem esteja determinada por outra (MOLANO; ALMEIDA, 2017 p.9).

$\mathrm{Na}$ escola, portanto, verificam-se movimentos docentes em busca da construção interdisciplinar, como uma possibilidade para práticas de EA. Como explana Figueira et al., 2017, p.4): "Por outro lado, também foi defendida a interdisciplinaridade como um caminho que permite que temáticas da EA sejam abordadas a partir do conteúdo de qualquer disciplina, necessitando, entretanto, do comprometimento por parte do professor".

Poucos trabalhos com proposições que exploravam temários e conteúdos próprios disciplinares foram apresentados com uma abrangência socioambiental, defendendo uma perspectiva crítica, embora muitos anunciassem algum diálogo com a perspectiva crítica de EA, mas não estabeleceram práticas nesse sentido. Isto que pode ser visto como o desejo docente de tornar a EA uma possibilidade de discussão mais politizada sobre a problemática ambiental, o que acaba não se realizando porque as abordagens, em geral, permanecem numa perspectiva reduzida da realidade. Muitas vezes, os textos contêm uma apresentação de referenciais com autores do campo crítico e da educação crítica, entretanto essas referências não direcionaram efetivamente, em sua maioria, as práticas realizadas.

A produção acadêmica busca apontar alguns referenciais teóricos para a EAC, mas sua realização prática não é tão disseminada. Pode-se supor, em parte pela necessidade, um maior aprofundamento conceitual e de discussão/reflexão das ações desenvolvidas. Esse é o contexto em que cabe refletir sobre o que é Educação Ambiental Crítica, definida por Loureiro e Layrargues (2013, p.64) como aquela que

[...] em síntese, busca pelo menos três situações pedagógicas: a) efetuar uma consistente análise da conjuntura complexa da realidade a fim de ter os fundamentos necessários para questionar os condicionantes sociais historicamente produzidos que implicam a reprodução social e geram a desigualdade e os conflitos ambientais; b) trabalhar a autonomia e a liberdade dos agentes sociais ante as relações de expropriação, opressão e dominação próprias da modernidade capitalista; c) implantar a transformação mais radical possível do padrão societário dominante, no qual se definem a situação de degradação intensiva da natureza e, em seu interior, da condição humana. 
A intenção em realizar atividades pedagógicas no contexto escolar, com essa perspectiva, esbarra nas práticas concretamente realizadas, muitas vezes de caráter descontextualizado, com ações individualizadas e proposições comportamentais. Na realidade, poderíamos afirmar que uma ação única não poderá conter a densidade e os parâmetros suficientes para caracterizar uma EAC. Assim, trata-se de um projeto de educação, algo que pressupõe uma continuidade, tempo e planejamento na escola.

A proposição da realização de diagnósticos participativos para produzir projetos coletivos com o desejo de englobar toda a comunidade escolar, que partam do diálogo com a realidade concreta até elaborar projetos de intervenção, também é elencado por autores como sugestão para a inserção da EAC na escola.

Os trabalhos que continham recomendações para o avanço da EAC e discussão de alguma prática partiam de uma perspectiva mais avaliativa, ou seja, um pesquisador de fora e com forte vertente teórica em relação aos trabalhos que se pautaram mais sobre as práticas escolares. Os trabalhos práticos, realizados pelos próprios pesquisadores, com pesquisa participante, em sua maioria não trazem referências para o avanço da EAC ou recomendações desse tipo, sugerindo a dificuldade até mesmo em reconhecer a macrotendência no sentido de Layrargues e Lima (2014), em que se insere sua proposta.

\section{Algumas considerações}

Após o estudo, podemos inferir que as macrotendências mais pesquisadas são a Educação ambiental crítica e a forma de se alcançar a ambientalização curricular, mediante práticas e metodologias participativas.

A formação inicial do professor dificilmente garantirá a inserção da perspectiva crítica da educação ambiental em seu acervo de conhecimentos, mas através de sua prática cotidiana e formação posterior/continuada, abre-se essa possibilidade. Assim, é imensa a importância de encontros como o EPEA para os professores interessados em desenvolver discussões sobre as questões socioambientais em suas práticas escolares. Tais encontros podem fornecer uma orientação das perspectivas presentes em outros profissionais que atuam com a educação ambiental na escola e tornam-se em si mesmos um espaço de formação.

Nesse sentido, esta coordenação sugere como incentivo a autoformação, a participação de docentes da educação básica nos encontros do EPEA, no sentido de ampliar a penetração das discussões desenvolvidas no GDP de EA no contexto escolar no cotidiano da educação formal.

\section{Referências}

ANDRADE, L.B.; PINTO, V.P.S. Discutindo os riscos e a vulnerabilidade ambiental no Estado capitalista: a proposta de uma Educação Ambiental como ato político. ENCONTRO PESQUISA DE EDUCAÇÃO AMBIENTAL, 9, 2017, Juiz de Fora. Anais... Juiz de Fora: UFJF, 2017. p.1-13. Disponível em: <http://epea.tmp.br/epea2017_anais/pdfs/plenary/0139.pdf>. Acesso em: 15 mar. 2018.

ARAUJO, Maria Inêz Oliveira. A dimensão ambiental nos Currículos de formação de Professores de Biologia. 2004. p. 208. Tese Doutorado em Ensino de Ciências e Matemática - Programa de PósGraduação em Educação da Universidade de São Paulo, São Paulo, 2004. 
COSENZA, A.; KASSIADOU, A.; SÁNCHEZ, C. Educação Ambiental e Direitos Humanos: necessárias articulações a partir da justiça ambiental e da ecologia política. In: SILVA, A. M. M.; TIBIRA, L. (Orgs.). Direito ao Ambiente como Direito à Vida: desafios para a educação em direitos humanos. São Paulo: Cortez, 2014. p. 21-46.

COUTINHO, M.R.S.; DA LUZ, P.C. S.; SANTIAGO, L.F. Educação Ambiental: o fazer docente em uma Escola Pública do Município de Marituba. ENCONTRO PESQUISA EM EDUCAÇÃO AMBIENTAL, 9, 2017, Juiz de Fora. Anais... Juiz de Fora: UFJF, 2017. p.1-11. Disponível em: <http://epea.tmp.br/epea2017_anais/pdfs/plenary/0248.pdf>. Acesso em: 10 mar 2018.

FAZENDA, I.C.A. Integração e interdisciplinaridade no ensino brasileiro: efetividade ou ideologia. São Paulo: Loyola, 1979.

FIGUEIRA, M. R., LIMA, J. G. S.; SELLES, S. E. Educação ambiental crítica na relação universidade/escola: narrativas docentes. ENCONTRO PESQUISA DE EDUCAÇÃO AMBIENTAL, 9, 2017, Juiz de Fora. Anais... Juiz de Fora: UFJF, 2017. p.1-8. Disponível em: <http://epea.tmp.br/epea2017_anais/pdfs/plenary/0069.pdf>. Acesso em: 19 jan. 2018.

FREIRE, P. Pedagogia da autonomia. 25 ed. São Paulo: Paz \& Terra, 2002.

FREIRE, P. Pedagogia do Oprimido, 50 ed. São Paulo: Paz e Terra, 2011.

GRAÚDO, D.; GUIMARÃES, M. Pertencimento e Educação Ambiental: reflexões iniciais. ENCONTRO PESQUISA DE EDUCAÇÃO AMBIENTAL, 9, 2017, Juiz de Fora. Anais... Juiz de Fora: UFJF, $2017 . \quad$ p.1-11. Disponível em: <http://epea.tmp.br/epea2017_anais/pdfs/plenary/0035.pdf>. Acesso em: 19 jan. 2018.

GUIMARÃES, M. Educação Ambiental Crítica. In: LAYRARGUES, Philippe P. (Org.) Identidades na Educação Ambiental Brasileira. Brasília: MMA, 2004. p.25-34.

HERNÁNDEZ, F. Transgressão e mudança da educação: os projetos de trabalho. Porto Alegre: Artmed, 1998.

JAPIASSU, H. Interdisciplinaridade e patologia do saber. Rio de Janeiro: Imago, 1976.

LAYRARGUES, P. P.; LIMA, G. F. As macrotendências político-pedagógicas da educação ambiental brasileira. Ambiente \& Sociedade, São Paulo, v.17, n.1, p. 23-40, jan./mar. 2014.

LOUREIRO, C. F. B. O movimento ambientalista e o pensamento crítico: uma abordagem política. Rio de Janeiro: Quartet, 2003.

LOUREIRO, C.F.B. Crítica ao teoricismo e ao praticismo na educação ambiental. In: NETO, A. C.; MACEDO FILHO, F. D.; BATISTA, M. S. da S. (Orgs.). Educação ambiental: caminhos traçados, debates políticos e práticas escolares. Brasília: Liber Livro, 2010. p.15-32.

LOUREIRO, C.F.B. Educação Ambiental e educação para o desenvolvimento sustentável: polêmicas, aproximações e distanciamentos In:___ _ LAMOSA, R. de A. C. Educação Ambiental no Contexto Escolar. Rio de Janeiro: Quartet, 2015. p.35-67.

LOUREIRO, C.F.B.; LAYRARGUES, P. P. Ecologia política, justiça e educação ambiental crítica: perspectivas de aliança contra-hegemônica. Trabalho, Educação e Saúde, Rio de Janeiro, v.11, n.1, p.53-71, jan/abr. 2013. 
LOUREIRO, C.F.B.; FLORIANO, M.D. A construção do objeto de pesquisa em educação ambiental crítica: reflexões a partir de escolas municipais em Duque de Caxias, RJ. ENCONTRO PESQUISA DE EDUCAÇÃO AMBIENTAL, 9, 2017, Juiz de Fora. Anais... Juiz de Fora: UFJF, 2017. p.1-12. Disponível em: <http://epea.tmp.br/epea2017_anais/pdfs/plenary/0052.pdf>. Acesso em: 16 jan. 2018.

MOLANO, J.G.S.; ALMEIDA, R.O. Apontamentos para uma Educação Ambiental intercultural em escolas de Bogotá. ENCONTRO PESQUISA DE EDUCAÇÃO AMBIENTAL, 9, 2017, Juiz de Fora. Anais... Juiz de Fora: UFJF, 2017. p.1-13. Disponível em: <http://epea.tmp.br/epea2017_anais/pdfs/plenary/0104.pdf>. Acesso em: 20 mar. 2018.

MORIN, E. Os sete saberes necessários à educação do futuro. Tradução de Catarian Eleonora F. da Silva e Jeanne Sawaya. São Paulo: Cortez; 2 ed, 2000.

OLIVEIRA, A.C.B.; LOUREIRO, C.F.B. A categoria de espaço geográfico enquanto possibilidade na construção de uma educação ambiental crítica na geografia escolar. ENCONTRO PESQUISA DE EDUCAÇÃO AMBIENTAL, 9, 2017, Juiz de Fora. Anais... Juiz de Fora: UFJF, 2017. p. 1-10. Disponível em: <http://epea.tmp.br/epea2017_anais/pdfs/plenary/0179.pdf>. Acesso em: 08 jan. 2018.

ROSA, M.D., NOGUEIRA, M.L.S.L., SOUZA, J.P.T., ROCHA, P.N., PINK, J. e VIVERIO, A.A. As perspectivas de ambiente e de Educação Ambiental nos projetos de professores da Educação Básica em um curso de formação continuada. Ambiente \& Educação. v.22, n 2, p.88-108, 2017. Disponível em: < https://periodicos.furg.br/ambeduc/article/viewFile/7335/5095>. Acesso em: 10 jan.2018.

SPOLAOR, F.A.; CONSENZA, A. Problematizações socioambientais: o que dizem os projetos de Educação Ambiental elaborados e implementados por duas escolas da rede estadual de ensino pertencentes à jurisdição da SRE/Juiz de Fora. ENCONTRO PESQUISA EM EDUCAÇÃO AMBIENTAL, 9, 2017, Juiz de Fora. Anais... Juiz de Fora: UFJF, 2017. p.1-12. Disponível em: <http://epea.tmp.br/epea2017_anais/pdfs/plenary/0059.pdf>. Acesso em: 24 mar. 2018.

TOZONI-REIS, M.F. de C. Pesquisa-ação em Educação Ambiental. Pesquisa em Educação Ambiental, Rio Claro, v. 3, n. 1, p. 155-169, jan/jun. 2008. Disponível em: < http://www.periodicos.rc.biblioteca.unesp.br/index.php/pesquisa/article/view/6159/4516>. Acesso em: 14 mai. 2018.

TOZONI-REIS, M.F. de C.; CAMPOS, L.M.L. A formação inicial de professores no fortalecimento da educação ambiental escolar: contribuições da pedagogia histórico-crítica In: LOUREIRO, C.F.B.; LAMOSA, R. de A.C. Educação Ambiental no Contexto Escolar. Rio de Janeiro: Quartet, 2015. p.105-138.

VEIGA-NETO, A. Currículo e interdisciplinaridade. In: MOREIRA, A.F. (Org.): Currículo: questões atuais. Campinas. Papirus, 1997. 